\title{
Understanding weather and climate extremes
}

Eresanya Emmanuel Olaoluwa ${ }^{1,2}$, Olufemi Sunday Durowoju ${ }^{3}$, Israel R. Orimoloye ${ }^{4,5}$, Mojolaoluwa Daramola ${ }^{6,7}$, Akinyemi Akindamola Ayobami ${ }^{6}$ Olasunkanmi Olorunsaye ${ }^{2}$

\footnotetext{
${ }^{1}$ South China Sea Institute of Oceanology, Chinese Academy of Sciences, 164 West XingangRoad, Guangzhou 510301, People's Republic of China.

${ }^{2}$ Department of Marine Science and Technology, Federal University of Technology, P.M.B 704,Akure, Nigeria ${ }^{3}$ Department of Geography \& Resource Management, Faculty of Social Sciences Osun State University, Okokum, Osun State, Nigeria

${ }^{4}$ Centre for Environmental Management, Faculty of Natural and Agricultural Sciences, University of the Free State, 339, Bloemfontein 9300, Republic of South Africa

${ }^{5}$ Risk \& Vulnerability Science Centre, University of Fort Hare, Alice Campus, South Africa

${ }^{6}$ Department of Meteorology and Climate science, Federal University of Technology ,Akure, Nigeria

${ }^{7}$ Institute of Geographic Sciences and Natural ResourcesChinese Academy of Sciences.
}

Email: eresanyaemmanuel44@gmail.com,olufemi.durowoju@uniosun.edu.ng, orimoloyeisrael@gmail.com, damoclues@gmail.com,jollizle@gmail.com, olorunsayeolasunkanmi@gmail.com,

\begin{abstract}
The understanding of weather and climate extremes provides academics, decision makers, international development agencies, nongovernmental organizations and civil society the necessary information for monitoring and giving early warning to prevent or minimize the risks associated with weather related hazards. Different researches were carried out to provide vital information that will further enhance the assessment of vulnerability and its impacts. Lack of proper understanding of weather and climate extremes was realized to be responsible for the huge and devastating losses that could have being averted or minimized over the past decades. Different countries and institutions have put in place a number of ways to increase sensitization and awareness of weather extremes. This became necessary in order to reduce the losses associated with these extremes both on local and regional scales.
\end{abstract}

\section{a. Introduction: Definitions (weather and climate hazards \& disasters)}

In the modern times, human beings find themselves in a very complex environment and their activities are becoming more sensitive to weather and climate events through their abilities to make decisions and influence the environment (DOE, 1991). In the event of influencing the weather over the years, several unplanned changes caused by human activity are changing earth's atmosphere at an alarming rate. These are through the depletion of the ozone layer and by the increase in pollution and carbon dioxide in the atmosphere. The effects of these changes are severe in the atmosphere. Weather is the most consistent news item in our day-to-day 
activities. This prominence indicates the significance of weather in everyday life of people. Without the atmosphere, no life could exist.

Events of past years have shown that greater interest must be developed for the study of atmospheric science. Events like problems of pollution and the possibility of artificial modification of environment as well as the problem of world food resources in the face of burgeoning population have made man to be aware of the critical effect of climate fluctuations on man (Glasson et al., 1996). The advent of artificial satellites and the development of electronic computers have made it possible to study the atmosphere (Noble, 1988).

The importance of weather and climate to man cannot be ignored in any region one finds himself. Man has been studying stars, moon, the sun and other celestial bodies with his immediate environment from time immemorial. In fact, the importance of weather studies has made the assertion "what is weather worth" an underestimation. Nowadays, nobody asks such a question for the value of weather to man, his activities and life cannot quantified (Aremu, 2008). While environments have placed limitations on human activities, people have also changed their environment more productive for themselves by studying their atmospheric conditions.

The atmosphere, the laboratory of studying weather covers mankind and his abode (Wallace and Hobbs, 1977). All the atmospheric processes directly or indirectly influence man and also influence the other parts of the environment. Weather influences man as well as man influences weather through his action, works and lives. Weather and climate influence plants, animal and soil directly (Ayoade, 1988). So the knowledge of weather (and climate) to man should be a must and an everyday assignment for man lives with it, by it and in it (Mauder, 1970).

During World Climate Conference in 1979, the following definitions were adopted for weather and climate. Weather is defined as the complete state of the atmosphere at a particular instant in time and with the evolution of the state through the generation, growth and decay of individual disturbances while climate is the synthesis of weather at a given location over a period of about 30-35 years. Climate therefore refers to the characteristic condition of the atmosphere deduced from repeated obtained observations over a long period. Climate includes more than the average weather conditions over a given area. It includes considerations of departures from average (i.e. variabilities), extreme conditions, and the probabilities of frequencies of occurrences of given weather conditions. Therefore, an extreme weather or 
climate event is generally defined as the occurrence of a value of a weather or climate variable above or below a threshold value near the upper or lower ends ('tails') of the range of observed values of the variable. Climate extremes such as droughts, floods, storms, heatwaves may be the result of an accumulation of weather or climate events that are, individually, not extreme themselves (though their accumulation is extreme) (Seneviratne et al., 2012).

The report of the Intergovernmental Panel on Climate Change averred that our climate and its extremes are changing (IPCC, 2013). A changing climate leads to changes in the frequency, intensity, duration, spatial extent and timing of weather and climate extremes, and can lead to unprecedented extremes. Likewise weather or climate events, even if not extreme in a statistical sense, can still lead to extreme conditions or impacts, either by crossing a critical threshold in a social, physical or ecological system, or by occurring simultaneously with other events. However, not all extremes necessarily result to serious impacts but a weather system such as tropical cyclone can have an extreme impact, depending on where and when it approaches landfall, even if the specific cyclone is not extreme relative to other tropical cyclones. (Seneviratne et al., 2012). Hence, reliable predictions of extremes are needed on short and long time scales to reduce potential risks and damages that result from weather and climate extremes (Seneviratne et al., 2012; IPCC, 2013; Chen et al., 2018)

Understanding weather and climate extremes is recognized as a major area necessitating further studies in climate research and has thus been selected as one of the World Climate Research Programme (WCRP) Grand Challenges, which is hereafter referred to as the Extremes Grand Challenge (Zhang et al., 2014; Alexander et al., 2016; Sillmann et al., 2017; Chen et al., 2018). This will further provides academics, decision makers, international development agencies, non-governmental organizations and civil society the necessary information for monitoring and giving early warning to prevent or minimize the risks associated with weather related hazards. It is worthy to note that many weather and climate extremes are the result of natural climate variability (including phenomena such as El Niño-Southern Oscillation (ENSO)), and natural decadal or multi-decadal variations in the climate provide the background for anthropogenic climate changes. Even if there were no anthropogenic changes in climate, a wide variety of natural weather and climate extremes would still occur (Seneviratne et al., 2012; Chatzopoulos et al., 2019).

The changes in the weather and climate extremes vary across regions and for different types of extremes (e.g. temperature extremes, precipitation extremes, drought, heat waves, and storms). 
Consequently, the demand for information is often at its greatest in an event's immediate aftermath, requiring a quick response from the scholars. But apparently conflicting views can confuse the public, for example, that all weather events are affected by climate change (Trenberth, 2011; Stott et al., 2013, Daramola et al, 2017 ), or that it is not possible to ascribe an extreme weather event to climate change (Stott et al., 2013). The danger is that such potential confusion could subvert the credibility of the science of climate change. Consequently, there is a need for climate science to better inform decision makers, keenly aware of the need to protect life and property from the impacts of extreme weather and climate. The purpose of this paper therefore is to provide an overview for a wider audience of the society on the current state of weather and climate extremes and the potential ways forward based on the expert discussions.

\section{b. Physical processes of climate extremes, timing and types of extremes.}

To better understand the concept of climate extremes, climate change has to first understood, the two concepts are interrelated. Climate change refers to continuous change in the mean weather condition over a long time scale usually above a decade (Huber and Gulledge 2011). These changes influence the timing, frequency, intensity, duration and spatial extent of climate extremes and can result in more severe extreme conditions. Moreso, climate and weather conditions that are not extreme can still have extreme impacts if a certain threshold is crossed or through simultaneous occurrence (IPCC, 2012, Richard, 2015).

On the other hand climate extreme does not have a concise definition, extreme is ambiguous, it is relative in time and location (e.g. a hot day in the tropics would be different from a hot day in the mid-latitude). More so, it can be used to describe the property of a climate variable or its impact (Zwiers et al, 2013). However, climate extremes could refer to the values of a climate variable above (or below) a threshold near the tail of the variable distribution, which generally occur rarely (IPCC 2012, Zhang et al., 2014; Alexander et al., 2016; Sillmann et al., 2017; Chen et al., 2018).

Generally, speaking, climate extremes are climate events that occur rarely within a defined climate system with the inclusion of cyclones (Zwiers et al, 2013). More so, certain climate extremes such as drought and flood, result from accumulation of individual climate events that may not in themselves be extreme, although their accumulation is extreme (IPCC 2012). Many 
other climate extremes are a result of natural climate variability (phenomenon such as El Nino and Monsoon) that occur on decadal times scales, this means that even without anthropogenic induced climate change, climate extremes would still occur naturally (IPCC 2012). There are various kinds of climate extremes, having varying physical and environmental impacts and occurring at different space and times scales. These extremes can range from continental scale drought to wide spread heat-waves lasting several days to weeks as well as short term events such as flash floods and tornadoes due to short lived storms (Zhang et al, 2013).

Furthermore, the relationship between the kinds of climate extremes are arbitrary, as not all climate extreme events lead to environmental impact if there is no exposure to vulnerability. More so, the impact of any event would depend on the season, duration, intensity, vulnerability and simultaneous occurrence of climate extremes such as drought and heat waves.

Understanding the systems of climate extreme has received a lot of public attention in recent decades because of its social-economic importance and impacts (Müller and Kaspar, 2014, Albert et al, 2009, Huber and Gulledge, 2011). The adverse effects that stem from extreme climate events have affected many societies, this consequently have led to several studies. The impacts of climate extremes are more in developing countries than in the developed countries (Chen et al, 2018, Huber and Gulledge, 2011, Richard, 2015). It affects cost across several sectors, food production and security, water supply and management, energy, shelter, transportation and life and property management. Awareness on climate extremes are on the increase in recent years. The sustainability of the socioeconomic environment and its development depends on our understanding of climate extremes (Albert et al, 2009 and Richard, 2015). In the $21^{\text {st }}$ century, Climate extreme is expected to be more frequent and intense (IPCC 2007), some studies have attributed the observed increase in climate extreme events to global warming (Anita et al, 2019).

\section{MEASURING CLIMATE EXTREMES}

Generally, there is no unified definition for climate extremes or the extremeness of climate events. Müller and Kaspar (2014) reported that climate extremes are generally easy to recognize but difficulty to define, this due to the level of variability observed in climate extremes, which vary in duration, spatiotemporal coverage and socioeconomic impact. Climate 
extreme can be defined based on (a) rarity (b) intensity (c) severity (in terms of socioeconomic damage and number of casualties).

Some literatures in their quest to define climate extreme make use of extreme indices obtained from the probability of occurrence of a given factor or the extent to which it exceeds a given threshold (Zwiers et al, 2013 and Chen et al. 2018). Zwiers et al, 2013 defined extreme indices based on the number of days with Maximum or Minimum Temperature or Precipitation, below the $1^{\text {st }}, 5^{\text {th }}$ or $10^{\text {th }}$ percentile or above the $90^{\text {th }}, 95^{\text {th }}$ or $99^{\text {th }}$ percentile, for a given time frame (days, month, year or season) relative to a reference period (fig 1). Several other definitions are based on duration above a given threshold or persistence of climate extreme. The major advantage of using climate extreme indices is the possibility of comparison across regions and across climate models (Chen et al. 2018).

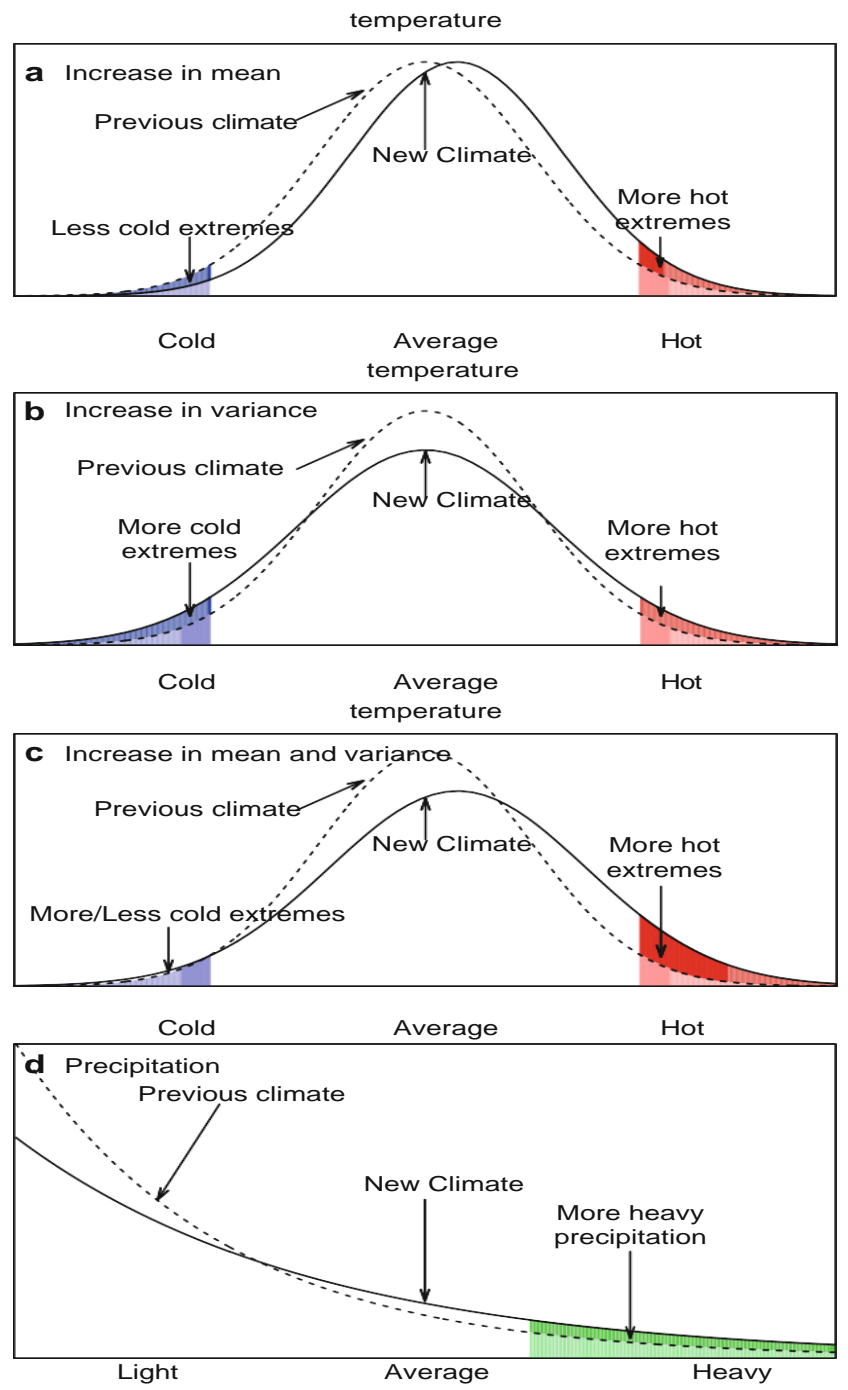


Fig 1.0: Representation of the distribution of daily temperature, indicating regions of extreme temperature and precipitation. (Source: Zwiers et al, 2013).

\section{EXTRME WEATHER CLIMATE VARIABLE}

\section{Temperature Extremes}

Temperature is associated with several kinds of climate extremes, ranging from heat waves to cold spells. These extremes have variety of impact on the environment, human health and natural ecosystem. For accurate analysis of temperature extremes, they are usually estimated on daily time scales (daily or more) as they occur on weather time scales. Many studies have been conducted regarding temperature extremes, especially heat waves. Heat waves occur as a result of atmospheric blocking or quasi-stationary anticyclonic circulation anomalies (IPCC, 2012). There is a high probability that since 1950, there has been a global scale decrease in the number of cold days and night and increase in the number of warm days and night, however with varying levels of confidence across continents (Chen et al. 2018).

Studies have shown that the current increase in warm spells is most likely a result of anthropogenic activities (Zwiers et al, 2013). Models projection has also shown that there would be an increase in the intensity, frequency and magnitude of hot extremes and a decrease in cold extremes over the course of the $21^{\text {st }}$ century globally. Based on this projection, the frequency and magnitude of warm spell and heat waves is bound to increase with more warm days (and nights) and less cold nights (and days) (IPCC, 2012, Eresanya et al., 2018).

Based on observation carried out, recent studies have categorized the hot days and night into three, daytime events (hot day-normal night), night time events (normal day-hot night), and complex events (hot day-hot night). More so, recent studies have discovered a new concept known as marine heat wave, which has had devastating impact on the marine ecosystem. However, very few studies exist on the subject matter, making it difficult to assign a concrete definition (Chen et al. 2018). Aside from heat waves, certain parts of the world (eastern china, North America and Central Eurasia) has experience increase cold waves during their winter season. None the less, there are still opposing views on the cause of such cold waves. A consensus is yet to be established due to lack of compelling evidence, thus making attribution and projections impossible (Chen et al. 2018).

\section{Precipitation Extremes}


Precipitation refers to water in its liquid or solid state falling from the clouds, in general, there are many kinds but the most significant are rain and snow. This section deals with the variation observed in daily precipitation or precipitation extremes. Precipitation extreme have the characteristic of being linked to different weather patterns and climate variations (El Nino and Monsoon), which usually defines their duration, intensity and trend (Chen et al, 2018). This variation in climate systems of different parts of the world makes it difficult to define precipitation extreme. Generally, studies make use of absolute threshold $(50.8 \mathrm{~mm} /$ day in the United States or $100 \mathrm{~mm} /$ day in china) or relative threshold (the $95^{\text {th }}$ percentile) (IPCC, 2012). Generally, results from precipitation extremes mostly have a medium confidence level due to the uncertainties arising from inaccurate understanding of the underlining climate variations.

Statistically speaking, current observation shows that it is more likely that precipitation extremes (heavy precipitation) has increased in more parts (regions) of the world than has decreased, however there are certain regional, sub regional and seasonal variation in the trend (Karl and Easterling, 1999). Similarly, there is also a medium confidence level concerning attribution studies, claiming that the global increase in extreme precipitation is linked to anthropogenic activities. Projection from models indicate the frequency and intensity of precipitation extremes (heavy precipitation) is set to increase over the course of the $21^{\text {st }}$ century in many parts of the world especially (tropics, northern mid-latitude in winter season and high latitude), whereas with a decrease in total precipitation (IPCC, 2012, Zwiers et al, 2013).

\section{Wind Extreme}

Winds, unlike temperature and precipitation are most times considered in their extreme state, in the form of tropical and extratropical cyclones, tornadoes and thunderstorms. Extreme winds speed can have very severe impact on infrastructure, the maritime and aviation sector as wells as influence water availability by increasing evaporation rate which can lead to drought. Wind on water bodies can influence coastal sea level, coastline stability and wave motion. Wind processes can also influence the formation and growth of arid and semiarid biomes, which defines the kinds of soil, and vegetation that emerges. The motion and position of forest fires are defined by the wind motion and in certain cases can lead to the formation of tornado genesis (IPCC, 2012, Osinowo et al, 2018). Wind extreme may be defined based on parameters such as high percentile, maxima over a particular time scale (daily or yearly), wind gust (measure of highest wind in a short time interval, usually 3 seconds), or storm related highest. Wind extreme variability is mostly affected by changes in local convective activity, movement of large-scale circulation patterns or associated phenomena. Observation of wind trend is rather 
uncertain due to shortcoming associated with anemometer readings and reanalysis data. Typically, because there are very few studies on the relationship between wind speed trend and extreme wind trend there is low confidence on projection of extreme wind with the exception of changes associated with tropical cyclones. More so, low confidence in projection of smallscale phenomena such as tornadoes arises from competing physical processes as well as the inability of models to simulate such phenomena (IPCC, 2012).

\section{CLIMATE PHENOMENON THAT INFLUENCE THE OCCURRENCE OF EXTREMES}

\section{Monsoon, El Nino and other Modes of variability}

There exists much uncertainty as regards climate change in monsoon regions especially regarding circulation and precipitation, however with few exceptions of some monsoon regions. The conclusions are drawn from very few studies, as there is no consensus between model representation of monsoon and its process creating high level of uncertainty (low confidence) in the projection of monsoon change. However, there is a high possibility of precipitation increase in monsoon regions (not all monsoon regions) which may not be a result of changes in the monsoon characteristics (IPCC, 2012).

The El Nino-Southern Oscillation (ENSO) is a natural climate variability caused by equatorial ocean-atmosphere interaction in the tropical Pacific Ocean. The resulting oscillation is associated with variation in the sea surface temperature (SST) in the east equatorial pacific. The El-Nino Phase is usually associated with warm SST in the east equatorial pacific while the La-Nina is associated with cool SST in the same region. Together the variation between the Ocean and atmosphere because of the El Nino and La-Nina is known as the ENSO and is usually associated with spatial patterns of weather extremes (heavy precipitation, extreme temperature, flood and drought). Invariably, monitoring and predicting ENSO using early warning system can lead to disaster risk reduction (IPCC, 2012).

Based on recent trends, there exist medium confidence towards more frequent El-Nino episodes in the central equatorial pacific, but too little evidence to make any deduction as regards ENSO. There is low confidence as regards projection of ENSO events because of inconsistencies in models that link its variability to increase in greenhouse gases. However most Global climate models project with medium confidence an increase in events within the central equatorial pacific which exhibits different patterns of climate variations than the classic eastern pacific 
(IPCC, 2012). There are several other climate variabilities that influences climate extremes aside from the monsoon and ENSO, they include; North Atlantic Oscillation (NAO), the Southern Annular Mode (SAM), and the Indian Ocean Dipole (IOD). There is low confidence in the ability of models to project changes in this circulation (NOA, SAM, IOD). The uncertainty arises from the inability of models to attribute the variability to stratospheric ozone or greenhouse gases. However, it is likely that there has been anthropogenic influence on SAM (due to trends in stratospheric ozone rather than greenhouse gases), while there is uncertainty regarding the influence of anthropogenic activities on NAO (IPCC, 2012)

\section{Storms}

Storms are powerful cyclonic activities, usually driven by latent heat release that occur in the atmosphere. Storms can occur on a range of scales from tornadoes to mesoscale convective complexes to tropical and extra-tropical cyclones. They cause severe damage that primarily results from high wind spend and heavy precipitation, additionally, damages could be compounded by flying debris, storm surges, high waves, drifting snow, wind driven ice movements and many more (Zwiers et al, 2013).

\section{Tropical Cyclones}

Tropical cyclones are the most common of extremes associated with wind speed, they occur over Tropical Ocean and pose major threat to population and infrastructure close to the coast, including offshore and shipping activities (IPCC, 2012). Since the inception of geostationary satellite, there remains, a constant number of 90 tropical cyclones observed annually. There is however variability in the frequency and location of their tracks within individual ocean basin. (Zwiers et al, 2013, IPCC, 2012).

Tropical cyclones cause more damage through storm surge and freshwater flooding than through heavy wind. However, the intensity of a tropical cyclone is measured based on its near surface wind speed usually on the Saffir-Simpsons scale, with the most dangerous wind in the category of $(3,4$ and 5) although they do not occur often. Aside from the intensity, the impact of tropical cyclones is dependent on the structure and the areal extent of the wind field, especially in the case of storm surge. Other relevant measure includes the frequency, duration, precipitation and track of the cyclone. When tropical cyclone tracks poleward, they can become extra-tropical cyclones (Zwiers et al, 2013, IPCC, 2012). 
There is low confidence as regards attributing changes in tropical cyclone activity to anthropogenic influences; this is because there are still lapses in understanding as regards the relationship between tropical cyclone and climate change, uncertainties in historical records of tropical cyclones, and the degree of tropical cyclone variability. Similarly, confidence remains low as regards the projection of the changes in tropical cyclone genesis, track, location, duration and area of impact. However, most models show that warming induced by greenhouse effect would likely increase the rainfall rate associated with tropical cyclones. It is also likely that the frequency of tropical cyclones would decrease or remain unchanged globally, similarly, it is likely that some tropical region would experience increase in the maximum wind speed of tropical cyclones, more so it is likely that the intensity of severe storms would also increase in some ocean basin (IPCC, 2012).

\section{Extra Tropical Cyclones}

Extratropical cyclones (synoptic-scale low-pressure systems) that occur within the mid-latitude in both hemisphere and are associated with extreme precipitation, storm surges, extreme winds, sea level and wave build up. They usually form over ocean basin within the proximity of upper tropospheric jets streams, through conversion from tropical to extra-tropical cyclones or as a result of flow over mountains. They majorly serve to convey heat and moisture from the tropics towards the poles and have major impact on regional temperature and precipitation (Francis W. Zwiers et al, 2013). Extra-tropical cyclones are formed and grow because of latent heat release from phase change of water and atmospheric instabilities (disturbance) along a zone of high temperature contrast (baroclinic instability). Such zones of baroclinic instability are rich in potential energy that can be converted to kinetic energy associated with extra-tropical cyclones. Detecting changes in extratropical cyclones is however, a major challenge because of inhomogeneity introduced through changes in the observing system. Observation indicate that over the last 50 years there exist the likelihood of a poleward shift in extratropical storms for both the north and southern hemisphere. Generally, there is medium confidence as regards the influence of anthropogenic activity on the changes to intensity, frequency and track of extratropical cyclones. Projection regarding extratropical cyclones is still quite uncertain because, difference in study technique, different (threshold, physical quantities, storm track and vertical level) of cyclone activity results in different projections (IPCC, 2012).

\section{Tornadoes}


Other kinds of small scale sever weather associated with wind are tornadoes and small-scale storms. Tornadoes are extreme events that result from high local vorticity produced within a thunderstorm resulting from convergence of angular momentum produced by rapid vertical motion. Although our understanding of the phenomena has greatly improved overtime there is however very limited research as regards the frequency and intensity of tornadoes globally. The limitation stems from inhomogeneity in report method, time and observatory platforms. The projection of future changes in the frequency and intensity of tornadoes remains uncertain because the influence of climate forcing such as greenhouse warming on tornadoes occurrence is not properly understood.

\section{CLIMATE OR WEATHER IMPACTS ON THE ENVIRONMENT}

\section{Hydrological Extremes}

The primary hydrological extremes discussed here are flood and drought, which affect a large number of people every year. Drought is of major significance because it can occur over continental scale with duration lasting years or longer. However, some kinds of floods are localized and occur over short duration while other can affect as large as a whole basin lasting month. These hydrological events although opposing in nature are not very mutually exclusive as they can occur simultaneously (Zwiers et al, 2013).

\section{Flood}

Flood is the overflow of water beyond the confines of a waterbody or the accumulation of water in areas are they are usually not present. The kinds of floods that exists are; (fluvial) floods, flash floods, urban floods, pluvial floods, sewer floods, coastal floods, and glacial lake outburst floods etc. floods are usually cause by intense, frequent and long-lasting precipitation, snow melt, dam break and local storms. Other factors that influence flood occurrence are soil properties, drainage basin conditions, the presence of snow and ice, urbanization, the existence of dams, dike and reservoir. In coastal environment, flood occurrence is influence by storm surge events, precipitation, glacial lake condition, sea level, snow cover, soil moisture, vegetation, presence of engineering development such as dikes and reservoir as well as land use (IPCC, 2012). Due to lack of evidence that stems from unavailability of instruments (spatially and temporally) as wells as the confounding effect of land use and engineering, there is low to medium confidence as regards climate driven observed changes in the frequency and magnitude of flood at a regional scale. Similarly, there is low confidence (due to lack of evidence) as regards the impact of anthropogenic influence on the frequency and magnitude of 
flood occurrence, however human activities had influenced precipitation and snow melt which are major contributors to flood occurrence. As regards projection of flood change, confidence is low due to lack of evidence, however there is medium confidence that rain fed flood may increase in some regions because of increase in heavy rainfall (IPCC, 2012).

\section{Drought}

Drought refers to a period of abnormally dry weather that causes hydrological imbalance. The primary cause of drought is lack of precipitation, however other influencing factors include; increased evapotranspiration, wind speed, vapour pressure deficit, previous condition of the soil moisture in terms of lakes, snow and ground water storage and land surface condition. There are four major forms of drought including; meteorological drought (lack of precipitation), agricultural (or soil moisture) drought and hydrological drought (runoff or streamflow).

It is however noteworthy to differentiate aridity from drought. Unlike drought or dryness, aridity is the characteristic of a pre-existing climate condition (e.g. desert). Studies make use of drought indices (proxies) to monitor and study changes in drought conditions as there are few direct observations of drought, such indices include; Palmer Drought Severity Index (PDSI), the Standardized Precipitation Index (SPI) and the Standardized Precipitation Evapotranspiration Index (SPEI) (Zwiers et al, 2013, IPCC, 2012). Through a feedback landatmosphere interaction, drought has the potential to affect extremes of other weather and climate elements such as precipitation, temperature and other variables. Based on the impact of anthropogenic activities on temperature and precipitation, there is medium confidence concerning the impact of anthropogenic activities on observed changes in drought conditions. Similarly, there is medium confidence that drought has become more severe in some parts of the world (South Europe and West Africa) and less severe in other parts of the world (North America and Northwest Australia).

Inconsistency in data and evidence makes it difficult to attribute observed change in drought condition on a regional scale. There is low to medium confidence as regards projected increase in the duration and intensity of drought in some parts of the world. Observation challenge for drought arises because of definitional uncertainty and lack of data, while projection challenges arise from the same issues plus the inability of models to include all the factors responsible for drought occurrence, uncertainty as regards the influence of climate forcing (e.g. El Nino) on drought occurrence and the land atmosphere feedback changes associated with drought. 


\section{Extreme Sea Level}

Extreme sea levels are caused by severe weather events (tropical and extratropical cyclones) that can lead to storm surges and extreme wave height at the coast. Atmospheric storminess and means sea level rise may contribute to futuristic changes in extreme sea level, although non-uniform spatially across the globe. Other factors such as glacial isostatic adjustments, variation in wind change, changes in atmospheric pressure, water density, and rate of thermal expansion, rapid melt of ice sheets, ocean circulation, coastal engineering and changes in earth's gravitational field can influence sea level change along coastlines. There also exists eternal variability that has transient effect on extreme sea level including; El-Nino Southern Oscillation, Pacific Oscillation, North Atlantic Oscillation and the position of the South Atlantic high (Zwiers et al, 2013, IPCC, 2012).

There are various methods used to characterise extreme sea level, such as storm-related highest values, annual maxima, or percentiles. Assessment based on limited data (low confidence) indicates a growing trend in coastal water that results from increase in mean sea level rather than change in storminess. It is also likely that anthropogenic influence on mean sea level is responsible for the observed increase in extreme coastal high waters. It is however possible that change in storminess contribute to changes in sea level extreme; however, uncertainties arise because of limited geographical coverage of studies and limited understanding of storminess change. Projected studies suggest the likelihood of constant rise in coastal high waters resulting from increase in mean sea level based on observed trends (IPCC, 2012).

\section{COMPOUND AND SIMULTANEOUS EXTREMES}

While considering the various kinds of climate extreme, it is of importance to consider the concepts of compound and simultaneous climate extreme. Although these climate events are less frequent than most extremes, their occurrence have however been spotted. Compound extremes can be defined as; (a) multiple extreme events occurring simultaneously or successively (b) combination of extreme events with underlying condition that intensifies the impact of the events. (c) Combination of events that are not in themselves extreme but their combination leads to extreme events or impact (Chen et al. 2018). For instance, the combination of heat wave and drought on wild fire, increased risk of flooding from intense precipitation and sea level rise. Compound extremes can also result from the combination of non-extreme or moderately extreme events, or even contrasting events such as drought and flood (IPCC, 2012). Simultaneous climate extremes are however different from compound 
extremes in that compound extreme occurs in the same location while simultaneous extremes occur at adjacent locations coincidentally. Simultaneous extremes are notorious for their magnitude and spatial coverage, posing a major challenge for organizations coping with disasters (Chen et al. 2018).

c. Measurement, detection and attribution of extremes.

Climate extremes are the potentially uncontrollable and unwanted outcomes of climatic variations and happenings on earth. Climate extremes include unexpected, unusual, severe, or unseasonal weather; weather at the extremes of the historical distribution - the range that has been seen in the past. Usually, climate extremes are detected based on a location's recorded weather history and defined as lying in the rarest percentiles. According to Wikipedia, there is evidence to suggest that human-induced global warming and subliminal heat activities are increasing the frequency and tenacity of some extreme climate events. This implies that the activities of mankind with regards to energy utilisation and acclimation, directly and indirectly affects the geosphere and concomitantly aggravates the extremity of climate changes.

Studies by Dokken et al, 2018, explains in more technical terms however that climate extremes are conventionally accepted as the occurrence of a value of a weather or climate variable above or below a limiting value near the higher or lesser end margins of the gamut of observed values of the variable. This is geometrically progressive and can only be appreciated on a statistical illustration. It explains that some forms of climate extremes (e.g., droughts, floods) may be the result of an accumulation of weather or climate events that are, distinctly, not extreme themselves. This further implies that climate extremes are additional results of morphing climate events that concatenate over time to become fill blown and seismic in statistical analysis and skews. As well, weather or climate events, even if not extreme in a statistical sense, can still lead to extreme conditions or impacts, either by crossing a critical threshold in a social, ecological, or physical system, or by occurring simultaneously with other events. The influence of tidal wave disparities in consistency along coastal lines is another complementary factor in the measurement and attribution of climate extremes.

Heim, 2016 in his research study on climate extremes opined that measuring, detecting and attributing climate extremes to globally and meteorologically accepted standards demands an insightful deposition that is evidenced by perpetual observation and meticulous team 
deliberation to create consensus. According to the Climate Change Committee accessment of 2020, assessing climate change is most commonly measured using the average surface temperature of the planet with alterations staying in the range of two standard deviations.

Further studies by Peterson and Menendez, 2019 shows that across the globe, land area as a whole there has been a measured overall decrease in the number of cold days and nights and overall increase in the number of warm days and nights. By effect, the diurnal balance has sank shallow and this has made the outlook of climate stability erratic and technically unpredictable. Even more, during the course of the research of Peterson and Menendez, more areas with increases than decreases in the frequency, intensity and/or amount of heavy rainfall were discovered with large parts of Europe, Asia, Eastern Africa and Australia and hinterland compartments of the globe as a whole have seen detectable increases in the frequency or length of warm periods. (Heim, 2016) explains that extreme weather-related events, such as droughts, heat waves, wildfires, large magnitude and intensity storms, floods, and blizzards, also appear to be associated with global warming. Left unresolved, the impact on ecosystems and human quality of life may be devastating.

The sociocultural practices of man has contributed largely to the amassment of climatic extremes. Whereas human civilization and activity has occurred during a period of what we now know has been a tolerable and relatively stable climate, the scale and efficiency with which we are extracting and burning carbon-rich fuel sources have created conditions outside the range of modern human experience. Risks to human health are among the most threatening of global warming-associated climate change, and are accelerating. These concerns in conjunction with impacts on ecosystems, urbanized areas, and community infrastructure contribute to heightened compulsion to act.

d. Environmental effects of the weather extremes.

Climate change including weather extremes influence global temperature and precipitation patterns. In turn, these impacts affect the severity and frequency of environmental threats, such as forest fires, hurricanes, heat waves, floods, droughts episodes, and land degradation, in some cases (Orimoloye et al 2019; Orimoloye et al 2021). Studies have shown that extreme weather events can decrease the carbon absorption potential of an ecosystem and create a dangerous cycle in which extreme weather fuels climate change by preventing carbon absorption by 
forests, causing more of it to stay in the atmosphere (Nunes et al., 2020). Records from the Intergovernmental Panel on Climate Change show that since the 1970s, the global average temperature has risen by at least 0.4 degrees Celsius ( 0.72 degrees Fahrenheit) and that by 2100 it could rise above pre-industrial temperatures to about 4 degrees Celsius (7.2 degrees Fahrenheit) (Koraim et al., 2011; Horton et al., 2020). While the global implications of climate change may seem too insignificant for people living around the world to notice, the consequences of climate change have already been witnessed through extreme weather events, including forest fires, hurricanes, droughts, heat waves, floods, and storms. Evaluation or modelling of real data has revealed that the intensity and frequency of these extreme events are influenced by climate change (Sarhadi and Soulis, 2017).

Environmental components and other human aspects have been identified to modified or influenced by extreme events. For instance, risks for wildlife, a decline in ecosystem functioning, land degradation, biodiversity and wetland extinction among others (Table 1) have been influenced or affected by extreme events (Maxwell et al., 2019; Orimoloye et al, 2020a). However, a lots still need to be done to confirm the actual relationship between climate change and extreme environmental events. Nevertheless, climate change or extreme event has not been proven to directly cause individual extreme environmental events, but has been identified to make these events more destructive, and likely happen more frequently, than they normally would be (Gasper et al., 2011; Turco et al., 2014).

Table 1. Impacts of climate change and extreme events

\begin{tabular}{|l|l|l|}
\hline SN & Climate change and extreme events & References \\
\hline 1 & Increasing risk of drought: High temperatures can lead to increased & Vicente- \\
& $\begin{array}{l}\text { precipitation, evaporation and transpiration. Thus, as temperatures } \\
\text { rise, the probability of hydrological and agricultural drought }\end{array}$ & Serrano et al., \\
& 2010 ; Vicente- \\
\hline
\end{tabular}




\begin{tabular}{|c|c|c|}
\hline & $\begin{array}{l}\text { increases. Atmospheric rivers (narrow streams of moisture } \\
\text { transported into the atmosphere) can also be influenced by a } \\
\text { changing climate, which can particularly disrupt precipitation } \\
\text { patterns in any region. }\end{array}$ & $\begin{array}{l}\text { Serrano et al., } \\
\text { 2020; Stewart } \\
\text { et al., } 2020\end{array}$ \\
\hline 2 & $\begin{array}{l}\text { Increasing risk of biodiversity loss: Plant and animal life would be } \\
\text { more affected as climate change changes temperature and weather } \\
\text { patterns continue to increase. As temperatures continue to rise, } \\
\text { researchers predict that the number and variety of species that } \\
\text { characterise biodiversity will decrease considerably. The loss of } \\
\text { biodiversity due to climate change will alter the structures and } \\
\text { functions of environmental or ecological systems. }\end{array}$ & $\begin{array}{l}\text { Araújo \& } \\
\text { Rahbek, 2006; } \\
\text { Sintayehu, } \\
2018\end{array}$ \\
\hline 3 & $\begin{array}{l}\text { Increasing risk of forest fires: Climate change and the extreme } \\
\text { event has been the key factors in increasing the risk and extent of } \\
\text { wildfires in many regions of the world, for example, Western United } \\
\text { States. Climate change causes forest fuels (the organic matter that } \\
\text { burns and spreads wildfires) to become drier, and the number of } \\
\text { major fires in the western United States between } 1984 \text { and } 2015 \text { has } \\
\text { doubled. According to a recent NOAA-funded report, global change } \\
\text { from rising greenhouse gas emissions is expected to significantly } \\
\text { increase the likelihood of very big, destructive wildfires over the next } \\
\text { few decades. }\end{array}$ & $\begin{array}{l}\text { Barbero et al., } \\
\text { 2015; Jolly et } \\
\text { al., } 2015 \text {; } \\
\text { Williams et al } \\
2015\end{array}$ \\
\hline 4 & $\begin{array}{l}\text { Decrease in crop yield: Temperature rises can cause yield decreases } \\
\text { of between } 2.5 \% \text { and } 10 \% \text { across a variety of agronomic species } \\
\text { (Hatfield et al., 2011). Other climate assessments on crop yield have } \\
\text { provided differing results. Productivity can be dramatically impacted }\end{array}$ & $\begin{array}{l}\text { Hatfield et al., } \\
\text { 2011; } \\
\text { Hatfield, \& } \\
\text { Prueger, } 2015\end{array}$ \\
\hline
\end{tabular}




\begin{tabular}{|c|c|c|}
\hline & $\begin{array}{l}\text { by temperatures that are deemed extreme and fall below or above } \\
\text { particular thresholds at critical times during growth. Crop yield } \\
\text { would be decreased by chronic exposure to high temperatures and } \\
\text { other extreme events during the pollination stage of the potential } \\
\text { grain or crop harvest. }\end{array}$ & \\
\hline 5 & $\begin{array}{l}\text { Increase in mortality from heat waves: Prolong periods of extreme } \\
\text { heat, usually defined as heat waves, have been linked with a } \\
\text { substantial increase in mortality, and specific events have been } \\
\text { reported as public health disasters. Extreme heat can increase the risk } \\
\text { of other types of disasters. Rising temperatures and other climatic } \\
\text { components across the globe poses a threat to people, ecosystems and } \\
\text { the economy. }\end{array}$ & $\begin{array}{l}\text { Wolf et al., } \\
\text { 2010; Kovats } \\
\& \quad \text { Kristie, } \\
\text { 2006; Ropo et } \\
\text { al., } 2017\end{array}$ \\
\hline 6 & $\begin{array}{l}\text { Increase in energy demand: Climate change may alter the capacity } \\
\text { for energy production and energy demands. Changes in the water } \\
\text { cycle, for example, have an effect on hydropower, and high } \\
\text { temperatures increase the energy demand for summer cooling, thus } \\
\text { reducing the demand for winter heating. }\end{array}$ & $\begin{array}{l}\text { Lipson et al., } \\
\text { 2019; Takane } \\
\text { et al., } 2020\end{array}$ \\
\hline 7 & $\begin{array}{l}\text { Increase in multiple climatic hazards: Studies have identified that } \\
\text { climate change is already modifying the frequency and intensity of } \\
\text { many weather-related hazards. Climate change magnifies disaster } \\
\text { risk; it can increase the risk while reducing the resilience of } \\
\text { households and societies at the same time. }\end{array}$ & (IPCC, 2014) \\
\hline 8 & $\begin{array}{l}\text { Risk to the livelihood of indigenous people: Extreme events due to } \\
\text { climate change, which has a significant effect on the livelihoods of } \\
\text { the rural population, declining agricultural yields in warmer }\end{array}$ & UNISDR, \\
\hline
\end{tabular}




\begin{tabular}{|c|c|c|}
\hline & $\begin{array}{l}\text { environments can also contribute to migration to urban areas, } \\
\text { increasing the population exposed to natural hazards in such } \\
\text { locations. The risk of severe, widespread and irreversible impacts on } \\
\text { humans and ecosystems is increased by increasing rates of warming. } \\
\text { In communities with low development levels, risks are unevenly felt } \\
\text { and are typically greater for vulnerable individuals and communities. } \\
\text { It has been indicated that indigenous peoples are impacted by climate } \\
\text { change in distinctive ways, as well as by policies or acts aimed at } \\
\text { addressing it. Indigenous groups, on the other side, have a unique role } \\
\text { to play in climate change through their traditional knowledge and } \\
\text { professions, cutting across all climate mitigation and adaptation } \\
\text { efforts, as well as just transition policies. }\end{array}$ & $\begin{array}{l}\text { 2017; Etchart } \\
2017\end{array}$ \\
\hline 9 & $\begin{array}{l}\text { High risk of species extinction: There is a growing awareness of } \\
\text { anthropogenic climate change as one of the major threats to } \\
\text { biodiversity and to species. There are numerous and nuanced ways in } \\
\text { which climate change is likely to impact biodiversity, including the } \\
\text { loss or destruction of essential ecosystems and microhabitats, } \\
\text { changes in environmental thresholds, such as temperature, water } \\
\text { availability/quality, beyond those that can be tolerated by a species. } \\
\text { he loss of significant interactions between two unrelated species, or } \\
\text { the arrival of invasive species. Environmental disruption (e.g. } \\
\text { reproduction or migration), direct loss of individual species or even } \\
\text { populations as a result of extreme events. }\end{array}$ & $\begin{array}{l}\text { Thomas et al., } \\
\text { 2004; Dantas } \\
\text { et al., } 2020\end{array}$ \\
\hline
\end{tabular}


A growing population globally will lose their homes and be driven into poverty without planning for climate change-induced environmental hazards. Since 2008, an average of about 22.5 million individuals have been displaced every year by climate or weather-related incidents. One way to plan for significant environmental events is to create climatic evaluation that display the frequency and intensity of these events by using current and historical data records. It is also possible to use these assessments to predict when and where future incidents will take place and how disruptive they will be. With this detail, by warning individuals living in highrisk areas and providing disaster relief, we can plan for severe weather events. In combating climate related impact and environmental extremes, the influence of climate change can also be observed by simulating the effects of various greenhouse gas concentrations on the environmental components Consequently, it has been found that climate change has increased the risk of wildfires in some regions of the world (Luo et al., 2013), extreme heat in China (Huang et al., 2018), and drought in South Africa (Orimoloye et al., 2020b; Orimoloye et al., 2021). Continuous study and development in the attribution of extreme events will help us find out more specifically how extreme environmental events are influenced by climate change and how we could change this trajectory.

\section{References}

Alam, G. M. (2017). Livelihood cycle and vulnerability of rural households to climate change and hazards in Bangladesh. Environmental Management, 59(5), 777-791.

Albert M.G. Klein T., Zwiers, F.W., and Zhang, X. (2009). Guidelines on Analysis of extremes in a changing climate in support of informed decisions for adaptation. World Meteorological Organization.

Alexander, L. V., Zhang, X., Hegerl, G., \& Seneviratne, S. I. (2016). Implementation Plan for WCRP Grand Challenge on Understanding and Predicting Weather and Climate Extremes. In Extremes Grand Challenge. www.wcrp climate.org /images/ documents/grandchallenges/WCRP_Grand_\%0AChallenge_Extremes_Implementatio n_Plan_v20160708.

Araújo, M. B., \& Rahbek, C. (2006). How does climate change affect biodiversity? Science, 313(5792), 1396-1397.

Aremu, K. J. (2008). Understanding Weather and Climate. Cee Kay Bee Printers, Kaduna, 
Nigeria.

Ayoade, J. O. (1988). Introduction to Climatology for the Tropics. Spectrum, Ibadan.

Barbero, R., Abatzoglou, J. T., Larkin, N. K., Kolden, C. A., \& Stocks, B. (2015). Climate change presents increased potential for very large fires in the contiguous United States. International Journal of Wildland Fire, 24(7), 892-899.

Change, I. C. (2014). Mitigation of climate change. Contribution of Working Group III to the Fifth Assessment Report of the Intergovernmental Panel on Climate Change, 1454.

Chatzopoulos, T., Pérez, I., Zampieri, M., \& Toreti, A. (2019). Climate extremes and agricultural commodity markets : A global economic analysis of regionally simulated events. Weather and Climate Extremes, January. https://doi.org/10.1016/j.wace.2019.100193

Chen, Y., Moufouma-okia, W., Zhai, P., \& Pirani, A. (2018). Recent Progress and Emerging Topics on Weather and Climate Extremes Since the Fifth Assessment Report of the Intergovernmental Panel on Climate Change. Annual Review OfEnvironment and Resources, 43, 35-39.

Dantas, B. F., Moura, M. S., Pelacani, C. R., Angelotti, F., Taura, T. A., Oliveira, G. M., ... \& Seal, C. E. (2020). Rainfall, not soil temperature, will limit the seed germination of dry forest species with climate change. Oecologia, 192(2), 529-541.

Daramola, M.T., Eresanya, E.O., and S.C., Erhabor (2017): Analysis of Rainfall and Temperature over Climatic Zones in Nigeria. Journal of Geography, Environment and Earth Science International. Vol. 11(2), Article no.JGEESI.35304.

DOE, D. of the E. (1991). Policy Appraisal and the Environment. HMSO, London. Glasson, J., Riki, T., \& Chadwick, A. (1996). Introduction to Environmental Impact Assessment. ULC Press, London.

Eresanya, E. O., Ajayi1,V. O., Daramola, M. T. , and R. Balogun : Temperature Extremes over Selected Stations in Nigeria, Physical Science International Journal 20(1): 1-10, 2018; Article no.PSIJ.34637 ISSN: 2348-0130

Etchart, L. (2017). The role of indigenous peoples in combating climate change. Palgrave Communications, 3(1), 1-4.

Gasper, R., Blohm, A., \& Ruth, M. (2011). Social and economic impacts of climate change on the urban environment. Current Opinion in Environmental Sustainability, 3(3), 150157.

Hatfield, J. L., \& Prueger, J. H. (2015). Temperature extremes: Effect on plant growth and development. Weather and climate extremes, 10, 4-10.

Hatfield, J. L., Boote, K. J., Kimball, B. A., Ziska, L. H., Izaurralde, R. C., Ort, D., ... \& Wolfe, D. (2011). Climate impacts on agriculture: implications for crop production. Agronomy journal, 103(2), 351-370.

Horton, B. P., Khan, N. S., Cahill, N., Lee, J. S., Shaw, T. A., Garner, A. J., ... \& Rahmstorf, S. (2020). Estimating global mean sea-level rise and its uncertainties by 2100 and 2300 from an expert survey. NPJ Climate and Atmospheric Science, 3(1), 1-8.

Huber, D.G. and Gulledge, J. (2011). "Extreme Weather and Climate Change: Understanding 
the Link and Managing the Risk" Science and Impacts Program. Center for Climate and Energy Solutions: Arlington, VA.

http://www.c2es.org/ publications/extreme-weather-and-climate-change.

Huang, D., Zhang, L., Gao, G., \& Sun, S. (2018). Projected changes in population exposure to extreme heat in China under a RCP8. 5 scenario. Journal of Geographical Sciences, 28(10), 1371-1384.

IPCC. (2013). Climate change 2013: The physical science basis. In: Stocker, T.F., Qin, D., Plattner, G.-K., Tignor, M., Allen, S.K., Boschung, J., Nauels, A., Xia, Y., Bex, V., Midgley, P.M. (Eds.), Contribution of Working Group I to the Fifth Assessment Report of the. In T. F. Stocker, D. Qin, G.-K. Plattner, M. Tignor, S. K. Allen, J. Boschung, A. Nauels, Y. Xia, V. Bex, \& P. M. Midgley (Eds.), Contribution of Working Group I to the Fifth Assessment Report of the Intergovernmental Panel on Climate Change. (p. 1535). Cambridge University Press, Cambridge, United Kingdom and New York, NY, USA.

Jolly, W. M., Cochrane, M. A., Freeborn, P. H., Holden, Z. A., Brown, T. J., Williamson, G. J., \& Bowman, D. M. (2015). Climate-induced variations in global wildfire danger from 1979 to 2013. Nature communications, 6(1), 1-11.

Koraim, A. S., Heikal, E. M., \& Abozaid, A. A. (2011). Different methods used for protecting coasts from sea level rise caused by climate change. Current Development in Oceanography, 3(1), 33-66.

Kovats, R. S., \& Kristie, L. E. (2006). Heatwaves and public health in Europe. European journal of public health, 16(6), 592-599.

Lipson, M. J., Thatcher, M., Hart, M. A., \& Pitman, A. (2019). Climate change impact on energy demand in building-urban-atmosphere simulations through the $21 \mathrm{st}$ century. Environmental Research Letters, 14(12), 125014.

Luo, L., Tang, Y., Zhong, S., Bian, X., \& Heilman, W. E. (2013). Will future climate favor more erratic wildfires in the Western United States?. Journal of Applied Meteorology and Climatology, 52(11), 2410-2417.

Mauder, W. J. (1970). The Value of Weather Methuen. London.

Maxwell, S. L., Butt, N., Maron, M., McAlpine, C. A., Chapman, S., Ullmann, A., ... \& Watson, J. E. (2019). Conservation implications of ecological responses to extreme weather and climate events. Diversity and Distributions, 25(4), 613-625.

Müller, M. and Kaspar, M. (2014). Event-adjusted evaluation of weather and climate extreme. Nat. Hazards Earth Syst. Sci., 14, 473-483.

Noble, H. B. (1988). The Earth and the New System of Satellite. In The Coming Era in Science. L. B. New York.

Nunes, L. J., Meireles, C. I., Pinto Gomes, C. J., \& Almeida Ribeiro, N. (2020). Forest contribution to climate change mitigation: Management oriented to carbon capture and storage. Climate, 8(2), 21.

Orimoloye, I. R., Belle, J. A., Olusola, A. O., Busayo, E. T., \& Ololade, O. O. (2020b). Spatial assessment of drought disasters, vulnerability, severity and water shortages: a potential drought disaster mitigation strategy. Natural Hazards, 1-20. 
Orimoloye, I. R., Kalumba, A. M., Mazinyo, S. P., \& Nel, W. (2020a). Geospatial analysis of wetland dynamics: wetland depletion and biodiversity conservation of Isimangaliso Wetland, South Africa. Journal of King Saud University-Science, 32(1), 90-96.

Orimoloye, I. R., Ololade, O. O., Mazinyo, S. P., Kalumba, A. M., Ekundayo, O. Y., Busayo, E. T., ... \& Nel, W. (2019). Spatial assessment of drought severity in Cape Town area, South Africa. Heliyon, 5(7), e02148.

Orimoloye, I.R., Belle. J.A, Ololade, O.O (2021). Drought disaster monitoring using MODIS derived index for drought years: A space-based information for ecosystems and environmental conservation. Volume 284, https://doi.org/10.1016/ j. jen v m a n.2021.112028.

Osinowo, A.A., Okogbue, E.C., Eresanya, E.O. et al (2017): Evaluation of wind Potential and its trends in the Mid-Atlantic. Modeling Earth Systems and Environment. https://doi.org/10.1007/s40808-017-0399-4.

Richard R.H., (Jr) (2015). An overview of weather and climate extremes - Products and trends. Weather and Climate Extremes 10, (1-9).

Ropo, O. I., Perez, M. S., Werner, N., \& Enoch, T. I. (2017). Climate variability and heat stress index have increasing potential ill-health and environmental impacts in the East London, South Africa. Int. J. Appl. Eng. Res, 12(17), 6910-6918.

Sarhadi, A., \& Soulis, E. D. (2017). Time-varying extreme rainfall intensity-durationfrequency curves in a changing climate. Geophysical Research Letters, 44(5), 24542463.

Seneviratne, S. I., Nicholls, N., Easterling, D., Goodess, C. M., Kanae, S., Kossin, J., Luo, Y., Marengo, J., McInnes, K., Rahimi, M., Reichstein, M., Sorteberg, A., Vera, C., \& Zhang, X. (2012). Changes in climate extremes and their impacts on the natural physical environment. In C. B. Field, V. Barros, T. F. Stocker, D. Qin, D. J. Dokken, K. L. Ebi, M. D. Mastrandrea, K. J. Mach, G.-K. Plattner, S. K. Allen, M. Tignor, \& P. M. Midgley (Eds.), Managing the Risks of Extreme Events and Disasters to Advance Climate Change Adaptation (pp. 109-230). A Special Report of Working Groups I and II of the Intergovernmental Panel on Climate Change (IPCC). Cambridge University Press, Cambridge, UK.

Sillmann, J., Thorarinsdottir, T., Keenlyside, N., Schaller, N., Alexander, L. V., Hegerl, G., Seneviratne, S. I., Vautard, R., Zhang, X., \& Zwiers, F. W. (2017). Understanding, modeling and predicting weather and climate extremes: Challenges and opportunities. Weather and Climate Extremes, 18(October), 65-74. https://doi.org/10.1016/j.wace.2017.10.003

Sintayehu, D. W. (2018). Impact of climate change on biodiversity and associated key ecosystem services in Africa: a systematic review. Ecosystem health and sustainability, 4(9), 225-239.

Stewart, I. T., Rogers, J., \& Graham, A. (2020). Water security under severe drought and climate change: Disparate impacts of the recent severe drought on environmental flows and water supplies in Central California. Journal of Hydrology X, 7, 100054.

Stott, P. A., Allen, M., Christidis, N., Dole, R. M., Hoerling, M., Huntingford, C., Pall, P., 
Perlwitz, J., \& Stone, D. (2013). Attribution of Weather and Climate-Related Events. https://doi.org/10.1007/978-94-007-6692-1

Takane, Y., Ohashi, Y., Grimmond, C. S. B., Hara, M., \& Kikegawa, Y. (2020). Asian megacity heat stress under future climate scenarios: impact of air-conditioning feedback. Environmental Research Communications, 2(1), 015004.

Thomas, C. D., Cameron, A., Green, R. E., Bakkenes, M., Beaumont, L. J., Collingham, Y. C., ... \& Williams, S. E. (2004). Extinction risk from climate change. Nature, 427(6970), 145-148.

Thomas R.K. and David R.E. (1999). Climate Extremes: Selected Review and Future Research Directions. Climate Change 42: 309-325.

Turco, M., Llasat, M. C., von Hardenberg, J., \& Provenzale, A. (2014). Climate change impacts on wildfires in a Mediterranean environment. Climatic Change, 125(3), 369-380.

Trenberth, K. E. (2011). Attribution of climate variations and trends to human influences and natural variability. Wiley Interdisciplinary Reviews: Climate Change, 2(6), 925-930. https://doi.org/10.1002/wcc.142

UNISDR, C. (2015). The human cost of natural disasters: A global perspective.

Vicente-Serrano, S. M., Beguería, S., \& López-Moreno, J. I. (2010). A multiscalar drought index sensitive to global warming: the standardized precipitation evapotranspiration index. Journal of climate, 23(7), 1696-1718.

Vicente-Serrano, S. M., McVicar, T. R., Miralles, D. G., Yang, Y., \& Tomas-Burguera, M. (2020). Unraveling the influence of atmospheric evaporative demand on drought and its response to climate change. Wiley Interdisciplinary Reviews: Climate Change, 11(2), e632.

Wallace, J. M., \& Hobbs, P. V. (1977). Atmospheric Science: An Introductory Survey. Academic Press, London.

William R.T. (2014). Weather and climate extremes: Pacemakers of adaptation? Weather and Climate Extremes 5-6, (29-39).

Williams, A. P., Seager, R., Macalady, A. K., Berkelhammer, M., Crimmins, M. A., Swetnam, T. W., ... \& Rahn, T. (2015). Correlations between components of the water balance and burned area reveal new insights for predicting forest fire area in the southwest United States. International Journal of Wildland Fire, 24(1), 14-26.

WMO. (1979). Proceeding of the world Conference.

Wolf, J., Adger, W. N., Lorenzoni, I., Abrahamson, V., \& Raine, R. (2010). Social capital, individual responses to heat waves and climate change adaptation: An empirical study of two UK cities. Global Environmental Change, 20(1), 44-52.

Zhang, X. Gabriele H., Sonia S., Ronald S., Zwiers, F., Lisa A. (2013). WCRP Grand Challenge: Understanding and Predicting Weather and Climate Extremes

Zhang, X., Hegerl, G., Seneviratne, S., Stewart, R., Zwiers, F., \& Alexander, L. (2014). WCRP 
Grand Challenge: science underpinning the prediction and attribution of extreme events.wWw.wcrpclimate.org/images/documents/grand_\%0Achallenges/GC_Extreme S_v2.pdf.

Zwiers, F.W., Lisa V.A, Gabriele C.H, Thomas R.K., James P.K., Phillippe N., Neville N., Christoph S., Sonia I.S., and Zhang, X. (2013). Climate Extremes: Challenges in Estimating and Understanding Recent Changes in the Frequency and Intensity of Extreme Climate and Weather Events. Climate Science for Serving Society: Research, Modelling and Prediction Priorities, doi 10.1007/978-94-007-6692-1_13. 